Pengembangan Rekayasa dan Teknologi, Vol 13, No. 2, Desember 2017, pp 43-46

p-ISSN: 1410-9840 \& e-ISSN: 2580-8850

http://journals.usm.ac.id/index.php/jprt/index

\title{
ANALISIS TINGKAT KEBISINGAN TERHADAP AKTIVITAS BELAJAR MENGAJAR DI FAKULTAS TEKNIK UNIVERSITAS SEMARANG
}

\author{
${ }^{1}$ Fahrudin Ahmad, ${ }^{2}$ Iryan Dwi Handayani, ${ }^{3 .}$ Srihera Nurweni \\ ${ }^{1,2 .}$ Fakultas Teknik, Universitas Semarang, Jl. Soekarno Hatta Semarang \\ Email: fahrudinahmadfis@gmail.com
}

\begin{abstract}
ABSTRAK
Kegiatan pembelajaran atau belajar mengajar yang optimal sangat membutuhkan lingkungan yang kondusif, dan tenang karena dibutuhkan konsentrasi yang cukup tinggi pada prosesnya. Kawasan lingkungan kampus memerlukan lingkungan yang tenang dan tidak bising. Wilayah perkotaan sulit untuk mendapatkan lokasi kampus yang tenang. Penelitian ini mencoba mengungkapkan bagaimana evaluasi pada faktor kebisingan yang terjadi selama proses belajar mengajar. Penelitian dilakukan di Universitas Semarang. Metode penelitian yang digunakan adalah metode deskriptif analitik.

Penelitian menunjukkan bahwa gedung perkuliahan fakultas teknik (gedung A) Universitas Semarang menunjukkan tingkat kebisingan dari baku kebisingan yang telah ditetapkan sesuai dengan (Standar Kualitas Akustik Bangunan Sekolah). Selain itu pihak Universitas Semarang harus menetapkan aturan dan kebijakan untuk mengendalikan tingkat kebisingan yang dibakukan, untuk meningkatkan kenyamanan pada proses perkuliahan.

Dari hasil penelitian Tingkat kebisingan di area gedung A fakultas teknik Universitas Semarang belum sesuai dengan standar baku yang telah ditetapkan yaitu masih lebih besar dari $(55 \mathrm{~dB})$.

Kata Kunci : bising, aktivitas perkuliahan, standar kualitas akustik bangunan sekolah.
\end{abstract}

\section{PENDAHULUAN}

Salah satu sarana yang paling penting dalam kegiatan belajar mengajar mahasiswa adalah ruangan kelas. Ruangan kelas mempunyai peran penting terhadap proses pembelajaran mahasiswa. Penataan desain interior kelas sangat penting bagi kenyamanan pengguna kelas. Desain interior berkaitan dengan proses merencanakan, menata, dan merancang ruang-ruang interior yang ada di dalam sebuah bangunan, termasuk perabot dan pengaruhnya. Perabot atau furnitur yang ada di dalam ruang kelas dapat mempengaruhi psikologis penghuni. Maka dari itu, sarana kelas sangat penting bagi keberlangsungan pembelajaran di sekolah. Faktor penataan ruang kelas merupakan kunci untuk menciptakan lingkungan belajar yang optimal. Menurut Nugroho (2007) salah satu aspek dari kenyamanan belajar adalah motivasi. Salah satu gangguan yang dapat menyebabkan mahasiswa kehilangan kenyamanan belajar ialah tidak memiliki motivasi diri. Ruang kelas yang nyaman merupakan salah satu aspek yang dapat mendukung terciptanya suasana belajar mengajar yang kondusif. Hal ini demikian, karena mahasiswa akan lebih fokus dan berkonsentrasi pada proses belajar mengajar saja tanpa memikirkan hal-hal lain yang berkaitan dengan kondisi ruang kelas. Universitas semarang merupakan kampus yang berada di Kota Semarang, tepatnya beralamat di Jalan arteri Soekarno Hatta yang dekat dengan jalur arteri dan jalan Tol. Maka berdasarkan hal di atas, diperlukan sebuah penelitian yang mendalam agar dapat diketahui intensitas dan sumber kebisingan pada ruang kuliah. apakah kebisingan dapat berpengaruh terhadap aktifitas belajar di dalam kelas. Oleh karena itu, paparan di atas mendorong keingintahuan peneliti dalam meneliti " Analisis Tingkat Kebisingan Terhadap Aktivitas Belajar Mengajar Di Fakultas Teknik Universitas Semarang"

Bising (noise) dapat diartikan sebagai bunyi yang tidak diinginkan. Sedangkan bunyi adalah perubahan tekanan pada media udara atau media lain yang dapat diindera oleh alat pendengaran manusia. Perambatan gelombang bunyi mengalirkan energi dari sumber yang berupa gerakan atau getaran suatu benda di segala arah. Pada saat benda bergetar atau bergerak, sebagian kecil dari energinya akan hilang ke medium sekitarnya menjadi bunyi.

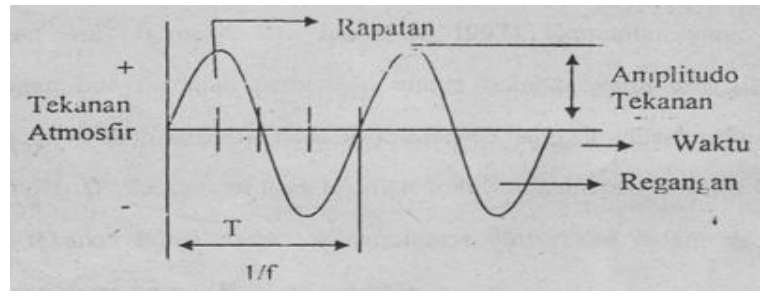

Gambar 1. Grafik perubahan tekanan bunyi terhadap waktu

Gelombang bunyi menyebabkan perubahaan tekanan pada medium yang dilewatinya. 
Berdasarkan Gambar 1, persamaan perubahan gelombang bunyi dapat dituliskan :

(i) $\quad P x=P \sin (k x-\omega t)$

Dengan $\mathrm{Px}=$ Perubahan dari tekanan standar $\mathrm{P}=$ Amplitudo tekanan

$\mathrm{k}=2 \pi / \lambda$ dengan $\lambda$ adalah panjang gelombang

$\omega=2 \pi f$, kecepatan sudut

Ada dua besaran yang biasanya diperoleh dalam bunyi yaitu frekuensi dan amplitude. Frekuensi adalah jumlah variasi tekanan per detik yang dinyatakan dalam satuan Hertz (Hz), sedangkan amplitudo adalah besaran yang menunjukan kuat lemahnya bunyi.

Kuat dan lemah suatu bunyi dapat ditunjukan dengan beberapa parameter yaitu intensitas bunyi (sound intensity), tekanan bunyi (sound pressure), aras tekanan bunyi (sound pressure level / SPL) dan kekerasan bunyi (loudness). Intensitas bunyi adalah waktu rata-rata aliran energi bunyi per satuan luas dengan arah tegak lurus terhadap bidang yang ditunjuk dan dinyatakan dalam satuan $\mathrm{Wm}^{-2}$. Kemudian yang dimaksud tekanan bunyi adalah perbedaan yang dinyatakan dalam satuan bunyi dengan tekanan atmosfir pada titik tersebut yang dinyatakan dalam satuan dari tekanan bunyi. Aras tekanan bunyi dinyatakan dalam decibel $(\mathrm{dB})$ dengan persamaan:

$$
S P L=20 L O G_{10}\left(P / P_{r e f}\right)
$$

Dengan :

SPL = aras tekanan bunyi $(\mathrm{dB})$

$\mathrm{P} \quad=$ tekanan bunyi yang diukur $(\mathrm{Pa})$

$\mathrm{P}_{\text {ref }}=$ tekanan bunyi referensi $(20 \mu \mathrm{Pa})$

Untuk mengetahui jumlah energi dari bunyi yang diukur dilakukan perhitungan rata-rata dari jumlah energi pada masing-masing frekuensi yang sudah ditetapkan yang dikenal dengan root mean squere. Berdasarkan persamaan (2.4) akan diperoleh hasil dlam satuan decibel $(\mathrm{dB})$, kemudian penentuan rata-rata aras tekanan bunyi di semua jangkauan frekuensi menggunakan persamaan:

$$
\begin{aligned}
& \text { SPL }=101010 \text { Log } \\
& {\left[\frac{1}{N}\left(10^{\left(\frac{S P L 1}{10}\right)}+10^{\left(\frac{S P L 2}{10}\right)}+\ldots . .+10^{\left(\frac{S P L N}{10}\right)}\right)\right]}
\end{aligned}
$$

Dimana:

$$
\begin{array}{ll}
\mathrm{SPL} & =\text { aras tekanan bunyi }(\mathrm{dB}) \\
\mathrm{N} & =\text { jumlah frekuensi }
\end{array}
$$

\section{METODE PENELITIAN}

Metode penelitian yang digunakan adalah metode deskriptif analitik, yaitu menguraikan fakta-fakta kebisingan yang terjadi di lingkungan ruang kuliah dengan mengukur tingkat kebisingan yang dilakukan oleh penyebab utamanya, kemudian dilanjutkan dengan membandingkan dengan standar baku kebisingan yang diijinkan.

\subsection{Waktu dan Tempat Penelitian}

Penelitian ini dilakukan di gedung A fakultas teknik Universitas Semarang selama 3 bulan, yaitu mulai bulan November 2017 - Januari 2018.

\subsection{Instrumen Penelitian}

1. Sound Level Meter (KRISBOW) tipe KW08291

\section{Timer/Stopwatc}

\subsection{Cara Kerja}

Dalam pengambilan data ini dilakukan pada lokasi berbeda, dimana pada masing-masing tempat dilakukan pengukuran sebanyak 8-10 kali dalam waktu 2 menit. Sehingga lamanya waktu yang dibutuhkan pada praktikum ini yaitu 20 menit. Dengan langkah-langkah sebagai berikut :

1. Memasangkan Micrifone pada Sound Level Meter.

2. Menekan tombol "POWER", lalu menunggu hingga angka pada monitor menjadi stabil (Perubahan tidak signifikan). Kira-kira selama 1-2 menit.

3. Setelah menganalisis jenis kebisingan yang akan diukur, tekan tombol "Fast/Slow". (pilihan Fast untuk jenis kebisingan kontinyu sedangkan pilihan Slow untuk jenis kebisingan terputus-putus).

4. Kemudian pada tombol "RANGE" pilih "AUTO" untuk menujukkan semua skala pengukuran.

5. Setelah 30 detik, tombol "HOLD" ditekan lalu mencatat hasil pengukuran yang ditunjukkan pada monitor SLM. Kemudian mengulangi langkah ini sebanyak 10 kali.

\section{HASIL DAN PEMBAHASAN}

\subsection{Data hasil Pengujian}

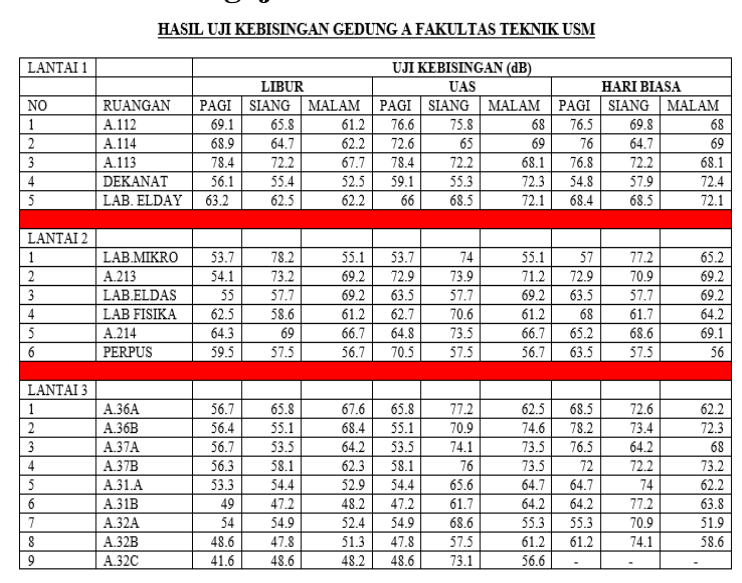




\subsection{Pembahasan}

Berdasarkan hasil pengujian kebisingan di gedung A fakultas teknik Universitas Semarang, maka evaluasi kebisingan yang terjadi pada ruang kuliah di gedung A fakultas teknik USM dengan melakukan identifikasi sumber kebisingan. Sumber kebisingan dapat berasal dari dalam maupun dari luar ruang kuliah. Sumber kebisingan yang berasal dari dalam ruang kuliah umumnya dapat ditekan dengan melakukan teguran secara langsung, seperti gaduh karena antar mahasiswa atau alat-alat yang menimbulkan bising di dalam ruang kuliah dapat diberi tindakan langsung. Sumber kebisingan yang ditimbulkan oleh sumber dari luar ruang kuliah seperti suara mesin diesel, kendaraan bermotor, klakson kendaraan yang lewat atau yang lainnya, memerlukan berbagai tindakan untuk mengatasinya.

Sumber kebisingan yang sering terjadi selain dari aktivitas di dalam ruang kuliah adalah kebisingan yang berasal dari aktivitas di luar ruang kuliah. Universitas Semarang terletak di tepi jalan raya Soekarno-Hatta dan berbatasan dengan jalan tol secara langsung. Adapun beberapa sumber kebisingan yang sering terjadi antara lain:

Suara kendaraan di jalan Tol, sumber kebisingan ini bersifat terputus-putus, sering disebut juga intermittent noise, yaitu bising yang berlangsung secar tidak terus-menerus, melainkan ada periode relatif tenang. Kebisingan ini relatif tidak dapat dikendalikan, karena sudah menjadi resiko yang harus diterima sehubungan lokasi kampus di pinggir jalan Tol Kaligawe- Gayamsari.

Suara gaduh pembicaraan mahasiswa di luar ruang kuliah, sumber kebisingan ini bersifat terputus-putus: sering disebut juga intermittent noise, yaitu bising yang berlangsung secar tidak terusmenerus, melainkan ada periode relatif tenang. Kebisingan ini relatif dapat dikendalikan dengan memberikan teguran kepada mahasiswa yang berada di luar ruang kuliah untuk berbicara secara pelan atau dapat juga dengan memberikan teguran agar pindah tempat duduknya.

Suara dari genset/ diesel dan suara pekerja pemotong keramik di sekitar area gedung A, sumber kebisingan ini bersifat kontinyu berjenis Norrow Spectrum yaitu bising yang relatif tetap, akan tetapi hanya mempunyai frekuensi tertentu saja, sehingga sangat mengganggu kegiatan perkuliahan.

\section{Pengukuran Kebisingan Pada Gedung A fakultas} teknik Universitas Semarang

Salah satu sumber kebisingan yang terjadi pada proses pembelajaran di USM adalah kebisingan yang diakibatkan dari aktivitas di luar ruang kuliah yaitu aktivitas kendaraan bermotor, genset, maupun aktivitas pekerja proyek bangunan. Aktivitas pemotongan keramik dan pengeboran beton ini sangat dikeluhkan oleh mahasiswa dan dosen, jika dilakukan pada waktu proses belajar mengajar dilakukan. Pengukuran kebisingan dilakukan dengan menggunakan alat Sound Level Meter. Pengukuran kebisingan dilakukan dengan menentukan titik pengukuran kemudian pengukuran dilakukan pada waktu yang berbeda dan dalam keadaan yang berbeda.

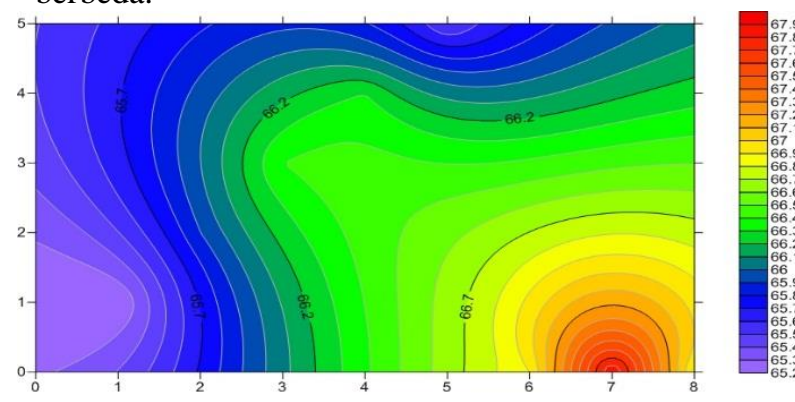

Gambar 2 Kontur ruangan A.214 di pagi hari (Hari biasa)

Berdasarkan hasil pengukuran tingkat kebisingan pada tiap titik, kemudian diolah dengan menggunakan software Golden Surfer 14 untuk menghasilkan peta kontur kebisingan.

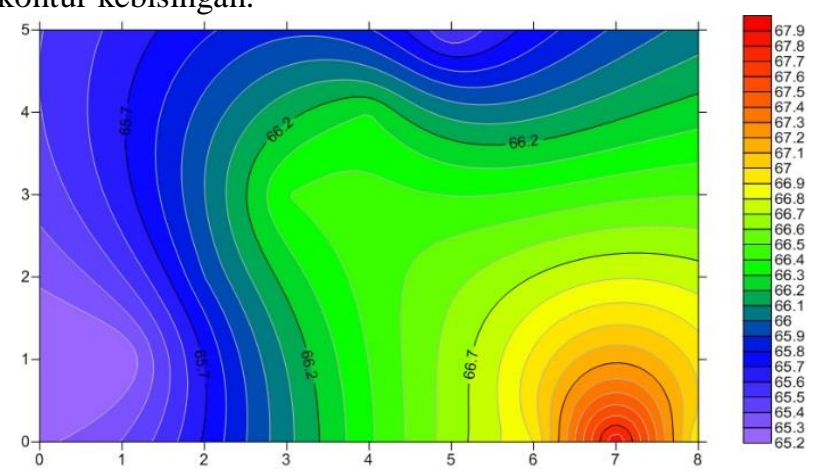

Gambar 2 Kontur ruangan A.214 di pagi hari (UAS)
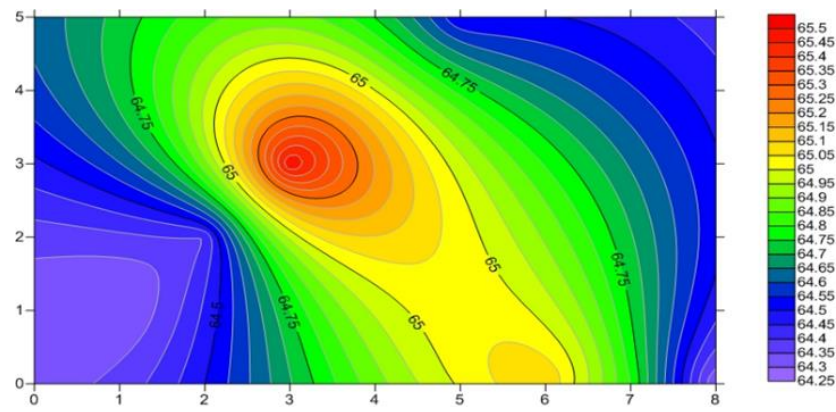

Gambar 3 Kontur ruangan A.214 di pagi hari (Libur)

Berdasarkan peta kontur kebisingan seperti gambar di atas, maka dapat dikatakan bahwa sewaktu pagi hari dalam kondisi yang berbeda maka terdapat perbedaan yang sangat berarti dari hasil pengukuran, hal ini dikarenakan adanya pengaruh kebisingan baik dari dalam maupun luar ruangan. Dari hasil 
pengukuran terlihat bahwa sebagian nilai kebisingan berada diatas $55 \mathrm{~dB}$, tentunya dalam hal ini kebisingan yang ada cukup mengganggu aktivitas proses belajar mengajar dilingkungan gedung A fakultas teknik USM. Kondisi ini sangat tidak dibenarkan jika dibandingkan dengan ketentuan yang telah ditetapkan sesuai dengan Keputusan Menteri Negara Lingkungan Hidup, No.48 Tahun 1996.

\section{SIMPULAN}

Dari penelitian yang telah dilakukan, diperoleh kesimpulan:

Tingkat kebisingan di area gedung A

fakultas teknik Universitas Semarang belum sesuai dengan standar baku yang telah ditetapkan yaitu masih lebih besar dari $(55 \mathrm{~dB})$.

Aturan dan kebijakan dapat dilakukan di lingkungan fakultas teknik untuk mengendalikan tingkat kebisingan di area gedung perkuliahan, sehingga meningkatkan kenyamanan perkuliahan.

\section{DAFTAR PUSTAKA}

Anizar, 2009, Teknik Keselamatan dan Kesehatan Kerja di Industri, Medan, Graha Ilmu.

Bridger, R.S., 2005, Introduction to Ergonomics (2nd ed.), New York, Taylor

Francis.Buchari, 2007, Kebisingan Industri dan Hearing Conservation Program, USU

Chandra, B., 2007, Pengantar Kesehatan Lingkungan, Jakarta, Penerbit Buku Kedokteran ECG

Dwi P. Sasongko, dkk, 2000, Kebisingan lingkungan, Semarang, Badan Penerbit Universitas Diponegoro.

Justian A., 2012, Analisis Pengaruh Kebisingan terhadap Performa Siswa Sekolah Dasar di Ruang Kelas [Skripsi], Depok, Program Studi Teknik Industri, Fakultas Teknik, Universitas Indonesia.

Menteri Negara Lingkungan Hidup, 1996, Baku Tingkat Kebisingan, Surat Keputusan Mentri Negara No: Kep. 48/MENLH/XI/1996, tanggal 25 November 1996, Jakarta, Meneg LH.

Mc. Cormick and Sanders, 1992, Human Factor in Engineering and Design, 7th Ed, New York, McGraw-Hill.

Munilson, Jacky; Edward, Yan; Hafiz, Al, 2009, Gangguan Pendengaran Akibat

Bising: Tinjauan Beberapa Kasus, Bagian Telinga Hidung Tenggorok Bedah Kepala

Leher, Padang, Fakultas Kedokteran Universitas Andalas-RSUP Dr. M. Djamil.

Nadya R.M.T, \& Poltje D.R, 2010, Gambaran Tingkat Ketulian pada Tenaga Kerja

Ruang Mesin PLTA Sektor Minahasa Wilayah Suluttenggo, Manado, Kesehatan Masyarakat Universitas Sam Ratulangi.
Notoatmodjo, S., 2003, Ilmu Kesehatan Mayarakat: Prinsip-Prinsip Dasar, Jakarta, Rineka Cipta.

Petinaung, J. K., 2008, Hubungan Lama Kerja dengan Gangguan Pendengaran Pada

Tenaga Kerja di Ruang Mesin PLN Kecematan Tabukan Selatan [Skripsi]. Manado. Politeknik Kesehatan.

Pawestri, T.A., dkk, 2010, Pengaruh Lay Out Bangunan pada Pereduksian Bising

Prasasto Satwiko, 2005, Fisika Bangunan 1, Edisi2, Yogyakarta, Penerbit ANDI.

Rambe, A., 2003, Gangguan Pendengaran Akibat Bising. Medan. (Online), http://www.thtkomunitas.org/index2.php?optio $\mathrm{n}=$ com_content\&do_pdf=1\&id=9), diakses tanggal 25 Juli 2014.

Sularti, S., 2010, Kajian Kenyamanan Audial pada Ruang Kuliah (Studi Kasus

Universitas Langlangbuana, Bandung), Jurusan Arsitektur, Fakultas Teknik, Universitas Lalangbuana. http://ejournal.kopertis4.or.id /file.php?file=karyailmiah \&id= 983, diakses tanggal 25 Juli 2014.

Walpole, R.E., 1995, Pengantar Statistika, Jakarta, PT. Gramedia Pustaka Utama.

Wignjosoebroto, Sritomo, 1992, Teknik Tata Cara dan Pengukuran Kerja, Jakarta, Penerbit Guna Widya. 